\title{
Tatit, Meschonnic e a tradução de Caipira (Marques; Macaraí 1992): diálogos e desafios iniciais
}

\section{Tatit, Meschonnic and the translation of Caipira (Marques; Macaraí 1992): initial dialogues and challenges}

Julio César Ribeiro dos Santos*

\footnotetext{
* Doutorando em Linguística (PPGL-UFSCar), sendo a canção sertaneja seu objeto de pesquisa. É membro do grupo de pesquisa LEETRA-CNPq, agência de fomento: CAPES.

E-mail: j.ribeiro90@hotmail.com

TradTerm, São Paulo, v.38, fevereiro/2021, p. 116-141 
Resumo: À luz do diálogo inicial entre a Semiótica da Canção (TATIT 2003; 2012) e Estudos da Tradução (JAKOBSON 2010; MESCHONNIC 2006; 2008), proponho a descrição e análise de alguns elementos textuais de canção Caipira (MARQUES 1992) presente no álbum Planeta Azul (CHITÃOZINHO \& XORORÓ 1992) e sua tradução, integrante do álbum Grandes Clássicos da Música Sertaneja, vol. I (CHITÃozInHo \& XORORÓ 2007). Busco enfatizar a interdependência entre categorias analíticas histórica e epistemologicamente tratadas pelos linguistas na ordem de sua discrição, e atento para que, conquanto aspectos estruturais elementares como letra, melodia e harmonia sejam preservados, o Ritmo, na condição de organização subjetiva e corpórea do discurso e apreendido na ordem do contínuo entre os níveis (MESCHONNIC 2006), permita a produção e reconhecimento de subjetivações e historicidades distintas.

Palavras-chave: Canção Sertaneja; Caipira de Marques e Macaraí; Estudos Linguísticos; Estudos da Tradução; Semiótica da Canção.

Abstract: In light of the initial dialogue between Semiotics of Song (TATIT 2003; 2012) and Translation Studies (JAKOBSON 2010; MESCHONNIC 2006; 2008), I propose the description and analysis of some text elements of the song Caipira (MARQUES 1992) present in the album Planeta Azul (CHITÃOZINHO \& XORORÓ 1992) and its integral translation of Grandes clássicos da música sertaneja vol. I (CHITÃOZINHO \& XORORÓ 2007). I seek to emphasize the interdependence between analytical categories historically and epistemologically treated by linguists in the order of their discretion and careful that, while elementary structural aspects such as lyrics, melody and harmony are preserved, the Rhythm, condition of subjective and corporeal organization of the discourse and apprehended in the order of the continuum between the levels (MESCHONNIC 2006), it allows the production and recognition of different subjectivities and historicities.

Keywords: Sertanejo song; Caipira by Marques and Macaraí; Linguistcs studies; Translation studies; Song Semiotics.

TradTerm, São Paulo, v.38, fevereiro/2021, p. 116-141

Número Especial - III JOTA

www.revistas.usp.br/tradterm 
No artigo Aspectos linguísticos da tradução (JAKOBSON 2010: 127), lemos que "o sentido de qualquer signo linguístico é sua tradução em um signo novo, alternativo". A tradução é tomada como processo o qual, ainda que não despojado de materialidade, destitui do signo uma significação que the seja intrínseca: tradução, aqui, equivale à produção ativa do sentido. Como consequências: a) podemos chamar de tradução "qualquer uso da língua (ou sistema semiótico) que reformule ou retrabalhe qualquer outra obra linguística (ou de um sistema semiótico)" (PYM 2017: 278); b) em fina sintonia com pensamento saussuriano a propósito da subordinação da significação pelo valor (SAUSSURE 2006), o sentido de um signo é somente estabelecido em sua relação com outros do mesmo sistema. Prescindo desta perspectiva para compreender os efeitos da subjetividade na linguagem na produção da diferença a partir da mesma estrutura e algumas de suas implicações na produção de singularidade.

Amparo-me em alguns elementos da complexa obra de Henri Meschonnic (2006; 2008) e sua proficuidade para os estudos linguísticos contemporâneos, sobretudo no enfoque à interdependência das contrapartes constitutivas das dicotomias saussurianas e às inter-relações que são caras ao terceiro elemento sustentado por categorias opostas no funcionamento do sistema linguístico. As mútuas implicações mostram-se também na relação entre a linguagem e corpo, em que o próprio da poética não se reduz àquilo que se diz (um referente), mas remete ao trabalho realizado com (na e pela) a linguagem e que apresenta consequências ao efetivamente dito. Se Michel Foucault (2008), em seu momento arqueológico, mostra-nos o homem como sujeito e objeto do conhecimento, em grande medida subjetivado pelos saberes hegemônicos dos enunciados científicos, Meschonnic (2006; 2008) sugere que somos, inicial e totalmente, subjetivados pela linguagem. A devida atenção à oralidade (MESCHONNIC 2006: 37-42), presente no falado e no escrito, no ordinário e no poético, propicia e indicia nuances dessa subjetividade, singularidade na multiplicidade que se serve da estrutura para sua realização e, dotada de um Ritmo particular, ao mesmo tempo produtor e produto, vivifica ou revivifica o que se faz com a linguagem e nela.

TradTerm, São Paulo, v.38, fevereiro/2021, p. 116-141

Número Especial - III JOTA

www.revistas.usp.br/tradterm 
Com distinções de enfoque cuja demarcação é necessária, a oralidade (em sua acepção mais corriqueira) é também discutida por Luiz Tatit (2003; 2012): a fala é o germe da canção, tipo textual que articula a estabilidade da música e a imprevisibilidade da fala ordinária. Propriedades da música e da linguagem verbal articulam-se e conferem ao cancionista ${ }^{1}$ um aparato estrutural para a produção de sua singularidade reveladora de sentidos e de si. Genericamente, é um cancionista aquele que compõe e interpreta, que cria ou recria, ou, finalmente, aquele que traduz - tomando, aqui, a tradução em sua acepção mais holística. Tatit (2003; 2012) demarca o lugar da canção popular nos estudos linguísticos e aponta para a irredutibilidade das formas que a constitui: o todo que produz sentido. Como Meschonnic $(2006,2008)$, Tatit (2012) indica para o contínuo, para a interdependência, para a interrelação entre canção (letra e melodia) e o corpo.

Em aspecto biográfico, Meschonnic e Tatit comungam teorizar em torno de atividades em cujos planos práticos estiveram imersos: além de linguista, Meschonnic foi poeta, tradutor e ensaísta; o linguista Tatit ocupa posição de destaque também como instrumentista e cancionista. A escolha do corpus cotejado diz respeito, em partes, ao meu percurso acadêmico (cf. SANTOS 2018; 2019), mas, também, à necessidade de produção bibliográfica sobre a canção sertaneja (cf. ALonso 2011). D. Treece (2003: 334-336) conclama a construção de uma história da música popular destituída da analítica derivada da tradição crítica textual e as inclusões e exclusões inerentes às suas acomodações.

Ofereço a seguir uma breve análise comparativa entre duas traduções da canção Caipira (MARQUeS; MACARAí 1992), ambas animadas pela dupla Chitãozinho \& Xororó, em álbuns intervalados por 15 anos. 0 índice de valor distintivo entre uma e outra consiste, em princípio, mas não somente, na opção do cancionista pela variação de prestígio (gravação de 1992) e por uma

\footnotetext{
1 Cancionista é aquele que articula a linearidade da melodia à linearidade duplamente articulada da linguagem verbal por meio de sua gestualidade oral, de modo que "o fluxo contínuo da primeira [melodia] adapta-se imediatamente às vogais da linguagem verbal, mas sofre o atrito das consoantes que interrompem sistematicamente sua sonoridade" (TATIT 2012: 12).
}

TradTerm, São Paulo, v.38, fevereiro/2021, p. 116-141

Número Especial - III JOTA

www.revistas.usp.br/tradterm 
variação diatópica do português brasileiro, o dialeto caipira (gravação de 2007). A discussão se fundamenta, sobretudo, num diálogo inicial entre alguns elementos da Semiótica da Canção (TATIT 2003; 2012) e certas noções legadas de Meschonnic (2006; 2008).

\section{Me orgulho, agora, de ser caipira}

O compositor sertanejo é, na grande maioria, desprovido de maior aptidão intelectual; ele pertence [...] à classe proletária. Ela [a música sertaneja] se diferencia da música popular pelo despreparo de seus compositores que, ao construírem o componente textual da canção, caem, quase sempre, com raríssimas exceções, no anedotário, no ridículo (CALDAS 1977: 66-67).

A epígrafe formula um enunciado que sintetiza o discurso hegemônico sobre o cancionista e cancioneiro sertanejo nos idos dos anos 1970 e que vigora nas mais diversas e clivadas formações discursivas vigentes em nossa sincronicidade. Waldenyr Caldas (1977: 3) concebe esse tipo de canção² como produto, faceta discursiva de um grande gesto social orquestrado por classes dirigentes, almejantes da paradoxal integração das camadas menos validas pelo consumo, na tônica da tirania do lucro. Destacam-se nesse agenciamento a figura de Cornélio Pires ${ }^{3}$ e membros da próspera iniciativa privada paulista dos anos 1920 (e.g. Antarctica, Grupo Rhodia) a quem se atribui o financiamento da passagem do 'artesanato caipira' para a 'música sertaneja'.

Privações e explorações historicamente impostas aos desvalidos e oprimidos reproduzem-se e agravam-se por meio de estigmas atribuídos aos seus hábitos de corpo, propriedades de língua, inflexões de voz e escuta (PIoveZanı 2020:18). A desvinculação de estigmas e o anseio de notoriedade pública lisonjeira foram propícios para que muitos artistas sertanejos em atividade nos anos 1960-70 se servissem de elementos então distintivos, como a sonoridade, passível identificação na apreciação espontânea, e, de forma

\footnotetext{
${ }^{2}$ Em Acorde na aurora: música sertaneja e indústria Cultural (CALDAS 1977), o teórico trata indistintamente e em relação sinonímica canção e música, posição a que não me filio neste trabalho.

3 Empresário paulistano responsável pelo agenciamento (produção/distribuição) e curadoria de artistas caipiras dos anos 1920-1930 (cf. CALDAS 1977:1-3).
}

TradTerm, São Paulo, v.38, fevereiro/2021, p. 116-141

Número Especial - III JOTA

www.revistas.usp.br/tradterm 
mais sintomática, no registro de linguagem verbal com a mobilização da variante de prestígio.

Chitãozinho \& Xororó não passam incólumes. Em entrevista semiestruturada ${ }^{4}$ com Cláudio Paladini ${ }^{5}$, soube do desejo de "não identificação com a música caipira” por parte da dupla nos idos dos anos 1970: “eles não queriam ser conhecidos como uma dupla caipira”, em alusão ao lastro pejorativo imputado a duplas sertanejas nos centros urbanos. Os artistas paranaenses almejavam, antes, a fuga dos estigmas; em fina sintonia, outra faceta, mais atinente aos interesses de mercado, leva a crer em certo desejo de domesticação dos textos com vistas a certa sofisticação que os adequasse às expectativas dos potenciais grupos consumidores na suposta próspera e desenvolvimentista década de 1970: como enfatizado por Paladini, “a música é, também, um entretenimento" e, desde Kant, sabe-se que aquilo que entretém não tem como ambição inicial a produção do conhecimento, de modo que cumpre ao produtor de entretenimento o justo esmero na fusão do novo com o familiar (Cf. HAN 2019: 20-30) em dada contingência social, histórica e discursiva. 6

A despeito de Fio de cabelo (MARCIANO; RossI 1982) promover a passagem da dupla para os níveis notórios de repercussão nacional, cumpre notar, sem negar aparências ou disfarçar evidências, que a viragem para a década de 1990 foi decisiva para Chitãozinho \& Xororó. Para além da agregação de público em apresentações e execuções públicas em rádios $F M$, a dupla selava contratos com gravadoras multinacionais numa colonização multifacetada carregada de bônus - melhor qualidade de produção, distribuição e consumo

\footnotetext{
${ }^{4}$ Método de elicitação de dados caro a pesquisas etnográficas em forma de uma entrevista na qual o pesquisador elenca tópicos norteadores e relevantes para a pesquisa e cujos passíveis de aprofundamentos e questionamentos emergem durante o encontro com o entrevistado (cf. CRESWEL 2010: 70-72).

${ }^{5}$ Multi-instrumentista, compositor e, desde o ano 2000, atua com a dupla Chitãozinho \& Xororó na direção musical. Parte da entrevista (11 out. 2019) foi gravada e, a segunda parte, a convivência com a banda em um show realizado em São Carlos/SP, registrada em um diário de campo, como experiência etnográfica. Harmonizamo-nos às normativas do Comitê de Ética e dispomos de autorização de Termo de Consentimento Livre e Esclarecido.

${ }^{6}$ Ainda que concorde com Han (2019), filio-me à tradição da Análise Crítica do Discurso (FAIRCLOUGH 2001: 65) para a qual a linguagem é uma forma de práticas sociais controlada por grupos sociais, os quais instituem comportamentos e posicionamentos a serem aprendidos e seguidos.
}

TradTerm, São Paulo, v.38, fevereiro/2021, p. 116-141

Número Especial - III JOTA

www.revistas.usp.br/tradterm 
bem como firmamento de parcerias que proveriam transferência de capital simbólico - e ônus, sobretudo no que diz respeito à autonomia artística.

O cenário parece inverter-se hoje: em termos táticos, os artistas tornam-se proprietários de seu próprio selo e não mais subordinados diretamente às deliberações de gravadoras $^{7}$; em termos estratégicos, acompanhamos a ascensão do streaming e suas potencialidades na distribuição de materiais artísticos, bem como o fortalecimento e complexidade de uma rede social que sustenta o estilo sertanejo da canção popular, atualmente, o mais consumido no Brasil. 8

\section{Incursão à semiótica da canção}

O refrão da canção Mano (Rezende et. al. 1998) diz: “Juntos nós fomos a voz de uma linda canção / (...) / mano, você é a letra e eu sou a melodia”. A metáfora do último verso, que alude à irredutibilidade de uma relação, comporta um enunciado constitutivo do saber epilinguístico também encontrado no discurso científico por, de algum modo, sintetizar a proposta de Luiz Tatit (2003; 2012) para o tratamento de texto de canção. Vejamos, a seguir, como compreender a articulação interdependente de sistemas semióticos distintos, na produção totalizante do sentido.

Tatit (2012: 12) assevera que sua proposta teórica não tem como objetivo apresentar um mecanismo de apreciação/valorização estética; pelo contrário, sua preocupação diz respeito a uma gramática da canção, uma gramática melódico-musical. A apreciação empírica de uma canção propicia a depreensão espontânea dessa gramática: quando integramos “unidades sonoras numa sequência do mesmo paradigma" (TATIT 2003: 7) e estabelecemos negações, distinções e diferenças, já somos capazes de discernir o que chamamos de 'estilos' (por ex. axé, pop, soul). Ademais, a

\footnotetext{
7 A história mostra-nos que as guerras não cessam, mas encaminham-se por outros meios (PIOVEZANI 2020: 78). Nesse sentido, cumpre notar que os direitos, antes pertencentes a uma única instância, a principal (FAIRCLOUGH 2001: 92), hoje se mostram diluídos em recursos os mais diversos, oriundos do empresariado.

8 "Sertanejo é o estilo mais ouvido por brasileiros no rádio, diz Ibope" [30 nov. 2013]. G1.Disponível em: http://g1.globo.com/musica/noticia/2013/10/sertanejo-e-o-estilo-maisouvido-por-brasileiros-no-radio-diz-ibope.html. Acesso 10 jan. 2021.
}

TradTerm, São Paulo, v.38, fevereiro/2021, p. 116-141

Número Especial - III JOTA

www.revistas.usp.br/tradterm 
gramática melódica dispõe de mecanismos de reiteração que parecem propor incitação mnemônica capaz de conter a imprevisibilidade do fluxo inexorável do tempo. Em apreciação empírica, também apreendemos a tonalidade musical, que produz efeito somático (tensão/relaxamento) antes mesmo da cognicidade. Tatit $(2003 ; 2012)$ orienta-nos para a relação entre inflexões de voz, prolongamentos de suas durações e o despertar tensão pelo próprio esforço físico, quase sempre correspondente a certa tensão emotiva: "o ouvinte já está habituado a ouvir a voz do cantor em alta frequência relatando casos amorosos, onde há perda ou separação em grau de tensão compatível" (TATIT 2003: 8).

O perfil melódico identificável alinha as vogais e é capaz de favorecer ou desfavorecer a depreensão do conteúdo linguístico com o qual o conteúdo melódico se inter-relaciona. Conforme veremos adiante, o prolongamento da duração das notas bem como o aumento de sua frequência produz os estados de passionalização (enunciados da ordem do /ser/). Seu avesso também pode ser descrito: ao se reduzir a duração das vogais e o campo de utilização das frequências, tem-se uma produção melódica mais segmentada pelos ataques consonantais e tem-se campo profícuo para a tematização (enunciados da ordem do /fazer/).

O cancionista é dotado de gestualidade oral na manobra simultânea que compreende a articulação da linearidade contínua da melodia e da linearidade articulada da linguagem verbal em sua entoação. Tatit (2003: 9) aponta para como o uso de figuras linguísticas contribui para a impressão mais acentuada de que a melodia se trata de uma entoação linguística e diz que a canção propõe nobremente a revivificação a cada execução: trata-se das figurativizações enunciativas. Cumpre notar que, para além dos dêiticos e embreadores, os timbres ${ }^{9}$ vocais são concernentes às figuras enunciativas. Essa gestualidade parece reveladora de indícios de subjetividade e parece indicativa de alguma agentividade, por ex., algo de exclusivo que 0

\footnotetext{
9 Em Os níveis de análise linguística (BENVENISTE 1995: 127-141), aprendemos que, na linguagem verbal, os elementos segmentáveis mínimos são os fonemas que constituem o signo e que estes são integrados por unidades diferenciais (merisma) enformadas de significação. Mutatis mutandis, a unidade mínima de análise na linguagem musical é a nota a qual integra unidades diferenciais, a saber: altura, intensidade, duração e timbre (DIETRICH 2006:3).
}

TradTerm, São Paulo, v.38, fevereiro/2021, p. 116-141

Número Especial - III JOTA

www.revistas.usp.br/tradterm 
cancionista faria da linguagem, em alguma sintonia com o Ritmo de Meschonnic.

Tatit (2012: 15) entende que o germe da canção é a fala (ou parole). Se diferentes entoações produzem diferentes sentidos na linguagem ordinária, na canção não seria distinto: a entoação estaria presente também onde se encontram as reiterações cantatórias e as inflexões passionais. Ao criar tensões melódicas, o cancionista tende a camuflar sua entoação:

a fala está presente, portanto, no mesmo campo sonoro em que atuam a gramática do ritmo [da música] fundando os gêneros e a gramática da frequência formando a tonalidade. A presença da fala é a introdução do timbre vocal como revelador de um estilo ou de um gesto passionalista no interior da canção. Se o ouvinte chegar a depreender o gesto entoativo da fala no 'fundo' da melodia produzida pela voz, terá uma compreensão muito maior do que aquilo que se ouve no canto... (TATIT 2003: 8-9, marcas do autor).

No que diz respeito à 'presença da fala', Tatit (2003; 2012) parece chamar a atenção para o espaço intermediário ocupado pela canção entre o plano da arte autônoma e o plano da linguagem ordinária. Oliveira (2012) desenvolve um profícuo modelo que tensiona os regimes de linguagem em que a canção aparece situada: (a) o plano prático: a linguagem do uso espontâneo, coloquial, que tem como objetivo o fim e o significado; (b) plano artístico: a autonomia, o código específico, a valorização dos processos, o significante. Em seu gesto oral, o cancionista realiza a tensão entre os planos em um modelo estético que nunca rompe com a fala do dia-a-dia, mas que também é capaz de lidar com impulsos contraditórios entre as regularidades inerentes à gramática da música e à gramática da fala.

Prescindi da Teoria Semiótica da Canção no intento de identificar o lugar da canção nos estudos linguísticos e busquei brevemente indicar as complexidades subjacentes à materialidade (quase) sempre retalhada em suas acomodações disciplinares mais tradicionais. Na próxima seção, buscarei traçar um diálogo inicial com Meschonnic (2006; 2008) que, tal como Tatit (2003; 2012) o faz com a canção, propõe uma reflexão mais ampla e interrelacionada dos fenômenos da linguagem verbal.

TradTerm, São Paulo, v.38, fevereiro/2021, p. 116-141

Número Especial - III JOTA

www.revistas.usp.br/tradterm 


\title{
3. À luz do Ritmo outro
}

\author{
Trata-se, simplesmente, de saber o que um discurso faz. Não o que ele \\ diz, mas o que ele faz, e como (MESCHONNIC 2006: 11).
}

Em sua crítica da linguagem ${ }^{10}$, Meschonnic (2006) põe-se em favor da totalização forma-conteúdo em detrimento dos pares binários e opostos derivados, parcialmente, da partilha platônica e reverberados em algumas possibilidades de leituras (as radicalmente estruturalistas) do compilado editorial Curso de Linguística Geral (SAUSSURE 2006). Elucida-se à interdependência. "A linguagem só fala da linguagem" (MESCHONNIC 2006: 4): esta frase, que constitui um período na publicação original, parece asseverar que somos todos subjetivados pela linguagem. Àquele que cria pela linguagem e àquele que se propõe a traduzir cumpririam, então, o exercício e a depreensão das diferentes possibilidades de subjetivação possibilitadas pelo aparelho formal de enunciação: superar partilhas, pensar o contínuo. Lugar da poiesis, ainda que se passe pela hermenêutica.

Ao tratar do Ritmo, Meschonnic (2006: 4 marcas minhas), de antemão, adverte ele que "não está em nenhuma palavra separadamente, mas em todas juntas, e é o gosto do sentido". Destituída a metáfora, o vocábulo 'gosto' alude ao campo semântico da gastronomia, em que o 'gosto' resulta da mistura de ingredientes e, ainda com um preponderante, seu fundamento encontra-se na 'mistura' e sua depreensão de um conjunto complexo de mecanismos anatomofisiológicos articulados. Uma complexa relação de mútuas implicações. É campo da visada sobre os processos e suas interrelações contínuas. Meschonnic não se mostra conservador em relação às inúmeras poéticas que se presentificam na língua e é favorável à aproximação antidogmática da teoria da linguagem e da teoria da literatura. Antidogmatismos e a busca pelo contínuo parecem colaborar na leitura do texto de canção, campo nebuloso em que a linguagem não é nem totalmente

10 Aufhebung: construção/desconstrução. Ou, ainda, a continuidade na contiguidade e a valorização dos processos.

TradTerm, São Paulo, v.38, fevereiro/2021, p. 116-141

Número Especial - III JOTA

www.revistas.usp.br/tradterm 
natural nem totalmente artificial (TATIT 2012: 23). No que atine à oralidade, parte também constitutiva do Ritmo e que é a física da linguagem (MESCHONNIC 2006: 11) somos convidados a pensar para além da oposição do falado versus escrito, somos postos no entremeio. Que fale Meschonnic (2006: 7, marcas minhas):

a oralidade é um trabalho, de si sobre si e para os outros. 0 ritmo, então, é uma missão do sujeito. A experimentação imprevisível da alteridade sobre a identidade. É por isso que a oralidade e o ritmo são a matéria e a questão da modernidade. Abandonar Platão. E casa de Hegel...

Ao tomar a linguagem como "um trabalho de si sobre si e para os outros”, chama-se a atenção para o vislumbre de nuances da subjetividade da (mas na e pela) linguagem em cuja missão do sujeito pode ser compreendida, de algum modo, em sua maneira - dotado de alguma exclusividade - de operar a linguagem, deixar que esta faça o que ela faz/pode fazer. Ritmo e oralidade são termos complementares: a oralidade distingue-se das acepções negativas tributárias à literatura: "uma organização retórica da linguagem, distintiva e distinta daquela dos textos escritos não pode ser afastada" (MESCHONNIC 2006: 47). A passagem dualismo excludente escrito/oral para a tripartição complementar escrito versus falado versus oral "permite reconhecer o oral como um primado do ritmo e da prosódia, com sua semântica própria, organização subjetiva e cultural de um discurso, que pode ser tanto no escrito como no falado" (MESCHONNIC 2006: 8).

A superação da oposição 'forma versus sentido'11 comporta certo avanço teórico com repercussões na maneira como interpretamos obras como o Curso de linguística geral (SAUSSURE, 2006) em suas ‘divisões tradicionais’ (os dualismos, as dicotomias, às quais muitas vezes não dedicamos atenção necessária), conduzindo à analítica do contínuo, “o contínuo mítico entre as palavras e as coisas” (MESCHONNIC 2006: 8) e à ausência de relações entre as mais diversas esferas constitutivas das produções subjetivas do sentido. 0

11 Casas da dialética hegeliana, as quais não podem ser tomadas senão segundo abstrações teóricas do fenômeno, quer em tese, antítese ou síntese.

TradTerm, São Paulo, v.38, fevereiro/2021, p. 116-141

Número Especial - III JOTA

www.revistas.usp.br/tradterm 
sujeito se torna sujeito pela linguagem. Não obstante, podemos subjetivar-nos de diferentes modos - a oralidade permite invenções de distintas subjetividades (por ex. Fernando Pessoa e seus heterônimos). Subjetivação e historicidade implicam-se mutuamente e decorrem, em nível empírico, do trabalho que se fez com a linguagem.

Meschonnic (2006; 2008), ao indicar na categoria 'Ritmo' a superação de leitura dualistas, parece chamar atenção para os aspectos formais próprio da poiseis e suas implicações na construção do sentido. Ressalta o modo com que as seleções frásticas (a Panrítmica) deslocam em nuances o sentido efetivamente dito. Por ser uma tradução intralinguística (JAKOBSON 2010: 65), indicarei como, seleções associativas, instituídas de valor e significação, exercem forças na constituição de duas subjetividades distintas no processo de tradução, as quais trazem historicidade e acabam por produzir diferenças no próprio processo.

Tatit (2002; 2013), como vimos, também parece chamar atenção para as inter-relações no ponto em que o texto de canção só pode ser dito com a melodia, gesto oral do cancionista e sua dicção. Meschonnic não tratou de canções ou traduções intralinguísticas, tampouco Tatit de tradução de canções, as análises subsequentes buscam o diálogo entre teorias gestadas em diferentes áreas dos estudos sobre Linguagem, mas que comungam o princípio do contínuo (continuum) frente a divisão na ordem do discreto.

\section{O caipira de Darcy Ribeiro, o Caipira de Joel Marques e Macaraí, os Caipiras de Chitãozinho \& Xororó}

Em O povo brasileiro, Darcy Ribeiro (1995) apresenta uma região brasileira chamada Paulistânia ${ }^{12}$, que viveu momentos de prosperidade financeira e explosão demográfica decorrentes do extrativismo do ouro pelas Bandeiras. Com a diáspora, já na primeira metade do século XX, o capital é

\footnotetext{
12 Em referência à divisão geográfica atual, a região descrita por Ribeiro (1995: 25-37) diz respeito aos estados de São Paulo, Minas Gerais, Paraná, Goiás, Rio de Janeiro e Goiânia.

TradTerm, São Paulo, v.38, fevereiro/2021, p. 116-141

Número Especial - III JOTA

www.revistas.usp.br/tradterm
} 
dirigido para o segundo setor e acentua-se a cisão entre os antigos mineradores: os enriquecidos foram para o agronegócio ou indústria emergente; os demais edificaram a riqueza dos primeiros e encontraram reintegração econômica, sobretudo em centros urbanos em formação.

Esse grupo social é o berço de Joel Marques e Macaraí (cancionistas a quem se deve a autoria ${ }^{13}$ da canção), e também de José e Durval (doravante Chitãozinho \& Xororó), os quais migram ainda crianças de Astorga/PR para Mauá/SP, subúrbio operário paulista, nos fins dos anos 1960 e prestam-se a serviços caros ao proletariado em paralelo com a carreira artística incipiente (NeIVA 2002: 14-15): em sintonia com Ribeiro (1995: 34) e Caldas (1977: 22), o caipira destituído de posses, é reintegrado socioeconomicamente no operário periférico.

Em seus aspectos estilísticos ${ }^{14}$, textos de canção sertaneja produzidos a partir da década de 1960 já apresentavam em seus arranjos elementos indiciários que apontam para alguma assimilação com estilos de canção estrangeiros, como guarânia, rancheira, polca; no campo textual/discursivo, predominavam-se a idealização amorosa, bucolismo e saudade de minha terra em formulações linguísticas cada vez mais assimiladas com a variante de prestígio. Após o sucesso da requintada canção Fio de cabelo (MARCIANO; RosSI, 1982) e já instituídos em boa medida de reconhecimento social/midiático, os artistas parecem querer desvelar orgulhosamente o antes dissimulado (Cf. 1 supra): ser caipira ${ }^{15}$.

Toda classificação é antes redutora e a distinção entre as variações constitutivas do estilo de canção sertaneja não passaria incólume; no entanto, o esforço faz-se necessário para evitarmos mal-entendidos. Quando

\footnotetext{
${ }^{13}$ Entendo o autor como uma construção discursiva datada do século XVI, visando instituir a responsabilidade sobre o dizer e, também, prover consequências, dentre as quais receitas, àquele que disse (CHARTIER 2012: 20-30). A demarcação faz-se necessária somente para distinguir os papéis de autor e intérprete, já assumindo, de antemão, que ambos são cancionistas.

${ }^{14}$ Por enquanto, compreendo por 'estilo', o efeito da articulação de um plano da expressão em um plano do conteúdo gerando marcas relativamente estáveis e indivisíveis, passíveis de depreensão a partir da descrição de aspectos estruturais da linguagem musical e verbal.

15 Encontramos em discos precedentes menções ao campo e ao espaço rural. No período destacado, entretanto, os artistas já possuíam reconhecimento nacional. Entendo que revelar as origens ocultadas por outros meios (ex.: capas de discos e mesmo canções) implicava assumir certa dimensão de risco.
}

TradTerm, São Paulo, v.38, fevereiro/2021, p. 116-141

Número Especial - III JOTA

www.revistas.usp.br/tradterm 
recorremos à bibliografia, percebemos que Caldas (1977: 1-5) indica uma oposição geográfica e geopolítica, em que os produtos culturais exteriores ao Rio de Janeiro eram contemplados como 'sertanejos'. À luz do olhar modelado por autores da Escola de Frankfurt, Caldas (1977: 24-55) apresentanos à distinção entre os fenômenos rotulados 'sertanejos' a partir de: a) o 'artesanato caipira' (o sertanejo raiz); e b) o produto cultural industrialmente forjado (a canção sertaneja). Em uma esquematização sumária bastante voltada para a cronologia da emergência dos fenômenos, Schneider Caixeta (2016: 18-28) esquematiza subcategorias da canção sertaneja: a) sertanejo raiz (o caipira, até meados da década de 1970); b) sertanejo romântico, que emerge na passagem 1970-80, consolida-se na década de 1990, com declínio anunciado na segunda década de 2000; c) o sertanejo universitário, que ganha repercussão midiática no ano de 2005 com o trabalho de duplas César Menotti \& Fabiano, João Bosco \& Vinícius e perdura num complexo heterogêneo, incorporando estilos musicais nacionais e internacionais.

De minha parte e com alguma sintonia com Alonso (2011), tenho apostado na porosidade e no contínuo entre os estilos do amplo espectro da canção sertaneja. Eles podem ser contrastados pelas nuances mobilizadas para atualizações de conteúdos semelhantes no plano de expressão; de modo empírico, também podemos constatar maior estabilização do estilo sertanejo caipira/raiz frente ao romântico e ao universitário, de modo que, na prática de audição, reconhecemos facilmente estarmos diante de uma canção caipira, mas hesitamos em dizer se uma canção é sertaneja ou não.

Se o sertanejo raiz ou a canção caipira é fortemente identificada pela presença da viola caipira, motivos quase folclóricos, vozes que mesmo graves exploram zonas altas de tessitura, densidade rarefeita no fonograma e temas revestidos por figuras que constroem a isotopia figurativa do indivíduo rural (e.g. na linguagem musical, os pagodes e os rasqueados; nos aspectos linguísticos, o binarismo afetivo, o campo, o labor braçal), o estilo sertanejo romântico e, mais intensamente, o universitário, em seu constante e frenético desenvolvimento, parece comportar uma variação mais heterogênea e imprecisa de fenômenos, uma vez que incorpora elementos estilísticos do

TradTerm, São Paulo, v.38, fevereiro/2021, p. 116-141

Número Especial - III JOTA

www.revistas.usp.br/tradterm 
pop, do rock, forró e, recentemente, do funk, quer nos temas, quer nas figuras; não obstante, apesar da dispersão, lega características estilísticas próprias à canção caipira (por ex. exploração de altas frequências e notas longas, os temas afetivos), devidamente atualizados e revigorados pela tradução como procedimento poético de repetição. Sem buscar culpados ou inocentes, cumpre dizer que os investimentos os mais diversos - hoje certamente consolidados - aos quais a canção sertaneja foi subordinada acarretaram amplas repercussões em termos de produção, distribuição e consumo.

É no álbum Planeta azul (1992), vinculado à gravadora multinacional Polygram, que se encontra a primeira versão de Caipira (MARQUES; MACARAí 1992). Já a tradução de que me ocuparei aparece como quarta faixa do primeiro volume de Grandes Clássicos Sertanejos - Acústico, lançado no ano de 2007 e vinculado à gravadora nacional Radar Records. A distribuição também em DVD, suporte à época sofisticado, permite-nos assistir à dupla numa ostensiva fazenda situada nos pampas gaúchos. Ainda que se suponha, não há contradições entre o que se vê e o que se ouve, mas espaços estratégicos de produção de nova historicidade do caipira, vinculada, agora, à prosperidade e ao agronegócio e que contribui para a articulação do bloco ideológico hegemônico, ainda que o que se cante valorize seu avesso, como veremos. A execução da canção O caipira (MARQUES 1992) é precedida pelo seguinte diálogo:

Chitãozinho: Esta canção também é do nosso repertório, também é uma música antiga que tem uma história maravilhosa. Eu acho que o autor, Joel Marques, ele foi muito feliz quando ele escreveu as palavras do...o gosto do homem do campo, do homem da terra. Essa música se chama Caipira.

Xororó: Na verdade, a gente gravou essa música, mas a gravação que a gente fez alguns anos atrás a gente falou assim um português mais como a gente fala, como todo mundo fala aqui.

Ch: Errado! (risos)

$\mathrm{X}$ : Mas agora nós vâmo refazer porque a gente quer falar como o caipira fala. E ele fala mais ou menos assim...

Ch: Ele fala mais certo que nós!

Xororó: Com certeza!

Chitãozinho: Ele é autêntico!

TradTerm, São Paulo, v.38, fevereiro/2021, p. 116-141

Número Especial - III JOTA

www.revistas.usp.br/tradterm 
(CHITÃOZINHO \& XORORÓ, 2007)

Para além do saber epilinguístico e sua inter-relação com a partilha binária da ordem da moralidade vigente, Xororó, que “quer falar como o caipira fala", constrói por meio da linguagem uma subjetividade outra, que não é a dele. Propõe-se uma revivificação de um sujeito de outro tempo/espaço: uma subjetividade outra, o 'caipira de Darcy Ribeiro', que carrega e faz reviver, por meio do trabalho com o Ritmo, outra historicidade, o homem sertanejo. A distinção certo/errado (corrente no cotidiano e posta em tom derrisório por Chitãozinho) é igualmente formadora de preconceitos cujas raízes emergem do âmbito social, uma vez que a sociolinguística constata e descreve a existência de diferenças e variações de ordem linguística e sem implicações negativas em aspectos estruturais; por outro lado, a menção à 'autenticidade' parece cientificamente comprovável por remeter a certos aspectos linguísticos presentes no dialeto caipira e sua proximidade com fala dos eruditos do século XVII (RIBEIRO 1995:72). Vejamos, a seguir, a letra da canção O Caipira (MARQues; MACARAí 1992) em suas duas performances $^{16}$ :

O Caipira (Joel Marques; Macaraí 1992)

Álbum: Planeta azul (1992)

0 que eu visto não é linho

Ando até de pé no chão

E o cantar de um passarinho

É pra mim uma canção

Vivo com a poeira da enxada

Entranhada no nariz

Trago a roça bem plantada

Pra servir meu país
Caipira (Joel Marques; Macaraí 1992)

Álbum: Grandes Clássicos da Música

Sertaneja - Acústico (Vol. 1) (2007)

0 que eu visto num é linho

Ando até de pé no chão

E o cantar de um passarinho

É pra mim uma canção

Vivo com a poeira da enxada

Entranhada no nariz

Trago a roça bem prantada

Pra servi o meu país

\footnotetext{
${ }^{16}$ Destaco as distinções da ordem do dialeto em sublinhado.

TradTerm, São Paulo, v.38, fevereiro/2021, p. 116-141

Número Especial - III JOTA

www.revistas.usp.br/tradterm
} 
Sou, sou desse jeito e não mudo

Aqui eu tenho de tudo

E a vida não é mentira

Sou, sou livre feito um regato

Eu sou um bicho do mato

Me orgulho de ser caipira

Doutor, eu não tive estudo

Só sei mesmo é trabalhar

Nessa casa de matuto

É bem-vindo quem chegar

Se tenho as mãos calejadas

É do arado rasgando o chão

Se minha pele é queimada

É o sol forte do sertão.

(refrão)

Enquanto alguns fazem guerra

Trazendo fome e tristeza

Minha luta é com a terra

Pra não faltar pão na mesa

Às vezes vou a cidade

Mas nem sei falar direito

Pois caipira de verdade

Nasce e morre desse jeito
Sô, sô desse jeito e num mudo

Na roça nóis tem de tudo

E a vida num é mentira

Sô, sô livre feito um regato

Eu sou um bicho do mato

Me orgulho de ser caipira

Dotô, eu não tive estudo

Só sei memo é trabaiá

Nessa casa de matuto

É bem-vindo quem chegar

Se tenho as mão calejada

É do arado rasgano o chão

Se minha pele é queimada

É o sor forte do sertão.

(refrão)

Enquanto arguém faz guerra

Trazeno fome e tristeza

Minha luta é com a terra

Pra não fartá pão na mesa

Das vez eu vou a cidade

Mas nem sei falar direito

Pois caipira de verdade

Nasce e morre desse jeito

Apartado da melodia, o texto verbal apresenta certo requinte estilístico, o que desafia a constatação de Caldas (1977) (cf. 1 supra). As estrofes são constituídas regularmente por 8 versos heptassílabos, com exceção do refrão, composto por seis versos. Há regularidade nas rimas: quer nas internas, acentuadas nas proparoxítonas, quer naquelas dos finais dos versos. Há ainda figuras de estilo, como metonímia ("pé no chão", respeito à humildade), comparação (“é pra mim”), anáfora ("sou, sou desse...”), 
anacoluto e alusão ("se tenho as mãos calejadas / é o sol forte do sertão") e antítese ("enquanto alguns [...] minha luta”).

Em aspectos linguísticos, a tradução (2007) apresenta 15 distinções alusivas ao dialeto caipira, uma incorreção gramatical segundo a normapadrão (concordância nominal), e sutis, mas significativos, deslocamentos lexicais no qual se substitui um pronome por um nome e intensifica-se a historicidade evocada ("aqui eu tenho de tudo" (1992) e "na roça nóis tem de tudo" (2007). Deslocamentos da ordem da oralidade e implicações no ritmo e na Panrítmica: pelas deliberações nas relações associativas vistas eixo sintagmático, o sujeito do poema remete outra historicidade, mais rústica, em que se acentua o homem do campo. Cumpre dizer que a tradução não comporta exageros conducentes a estereótipos, portanto intensifica a verdade figurativa (TATIT 2012: 268).

Tião Lima ${ }^{17}$, cancionista e colaborador da tradução, ao lado de Chitãozinho, seu irmão, diz que a 'tradução para o caipirês' ocorreu no escritório da dupla, em Campinas, estado de São Paulo, quase informalmente, enquanto decidiam o repertório do álbum. A mudança do ritmo (MESCHONNIC 2006: 35-59) não parece ter-lhes sida desafiadora e torna-se indiciário que a opção dialetal não se reduz a uma escolha unicamente estilística. Embora hoje 'urbanizados', os cancionistas são migrantes nascidos em estratos sociais com menos recursos financeiros e, se não o foram, conhecem muito bem o sujeito da poesia: residiria na relação entre linguagem, corpo e historicidade a 'autenticidade' e fluidez da subjetivação?

Em se tratando de canção, tudo só é dito na tensão entre texto verbal, texto musical e também arranjo, grosso modo, melodias autônomas que se integram na constituição do fonograma (DIETRICH 2006:35); ou, ainda, processos persuasivos $^{18}$ que asseguram a regularidade do texto canção e interferem na produção do sentido. Em termos de materialidades musicais, o

17 Comunicação pessoal (CRESWELL 2010: 48) mediada por 13 mensagens via WhatsApp by Facebook e Direct (Instagram by Facebook) em setembro de 2019 permitiu conhecer com maior requinte de detalhes o processo de tradução da canção.

${ }^{18}$ A teoria semiótica nos mostra que tais processos persuasivos são compostos de relações tensivas entre aquilo que é da ordem da tematização, da passionalização e da figurativização (Cf. TATIT 2012: 7).

TradTerm, São Paulo, v.38, fevereiro/2021, p. 116-141

Número Especial - III JOTA

www.revistas.usp.br/tradterm 
texto de 1992 comporta viola caipira, violões de aço e nylon, bateria, percussão, contrabaixo elétrico e som de uma orquestra ${ }^{19}$. Trata-se de uma canção tonal (em Lá maior) numa célula rítmica de semínima no andamento de 108 batidas por minuto que asseguram a velocidade da melodia e harmonia.

O diagrama ${ }^{20}$ abaixo mostra-nos a disposição dos versos 1,2 (primeiro diagrama) e 15, 16 (segundo diagrama):
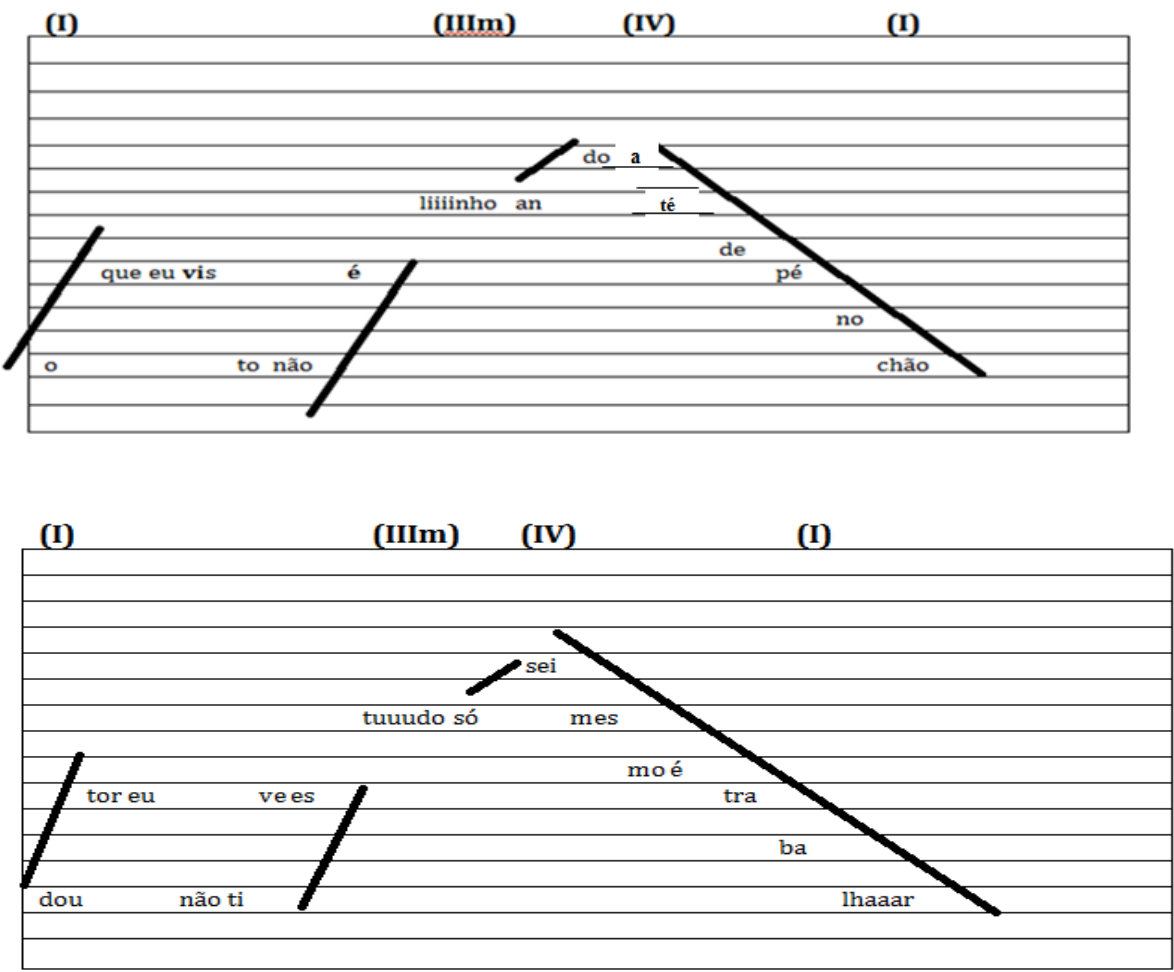

Notemos a presença de um perfil melódico cuja regularidade produz a reiteração da gramática melódico-musical. Atentemos também para a progressão harmônica da canção, que começa no grau I (repouso) e que se tensiona à medida que processos figurativos passionais se intensificam: ao cantar, por exemplo, a palavra 'estudo' (verso 15, diagrama 2), de modo extenso em duração e frequência, a harmonia encaminha-se para o grau IIIm, relativa menor do grau da função dominante (V), que supõe certa excitação psíquica (ouvida na melodia, na harmonia e na linguagem verbal) à canção. A

${ }^{19}$ Não me importo, para esta finalidade, se as próteses são reais ou virtuais. Importa-me mais o índice de valor do material sonoro, que alude à sofisticação e harmoniza-se aos padrões estéticos então hegemônicos.

${ }^{20}$ Em fidelidade ao modelo analítico de Tatit (2003; 2012), optei por traduzir a canção para o diagrama. Em função da exiguidade imposta, trago apenas alguns exemplos.

TradTerm, São Paulo, v.38, fevereiro/2021, p. 116-141

Número Especial - III JOTA

www.revistas.usp.br/tradterm 
maior frequência atingida é recoberta pelo acorde de função harmônica subdominante, que produz o ápice de tensão e parece querer 'relaxamento', atingido no regresso ao centro tonal melodicamente reproduzido.

No arranjo da tradução de 2007 elimina-se o prelúdio de quatro compassos atribui-se maior ênfase à figura da viola caipira e à fala/comentário que a precede. Encontramos maior suavidade em termos de processo persuasivo figurativo: instrumentos de percussão substituem caixa, tambores e pratos da bateria, exploração de sonoridades acústicas em acordeom, flauta, craviola e contrabaixo acústico. Sua célula rítmica preserva-se, no entanto, agora num andamento de 106bpm. Tais decisões contribuem para uma subjetivação mais genuína ou fiel às origens culturais (o dito caipira, 'sertanejo raiz') e exprimem maior efeito de verdade figurativa, indicando que a própria linguagem musical contribui para o efeito de produção da historicidade desejada. Vejamos, então, os contornos melódicos dos versos 1 e 2 (mostrados no primeiro diagrama) e 15 e 16, em seu subsequente, nesta versão:
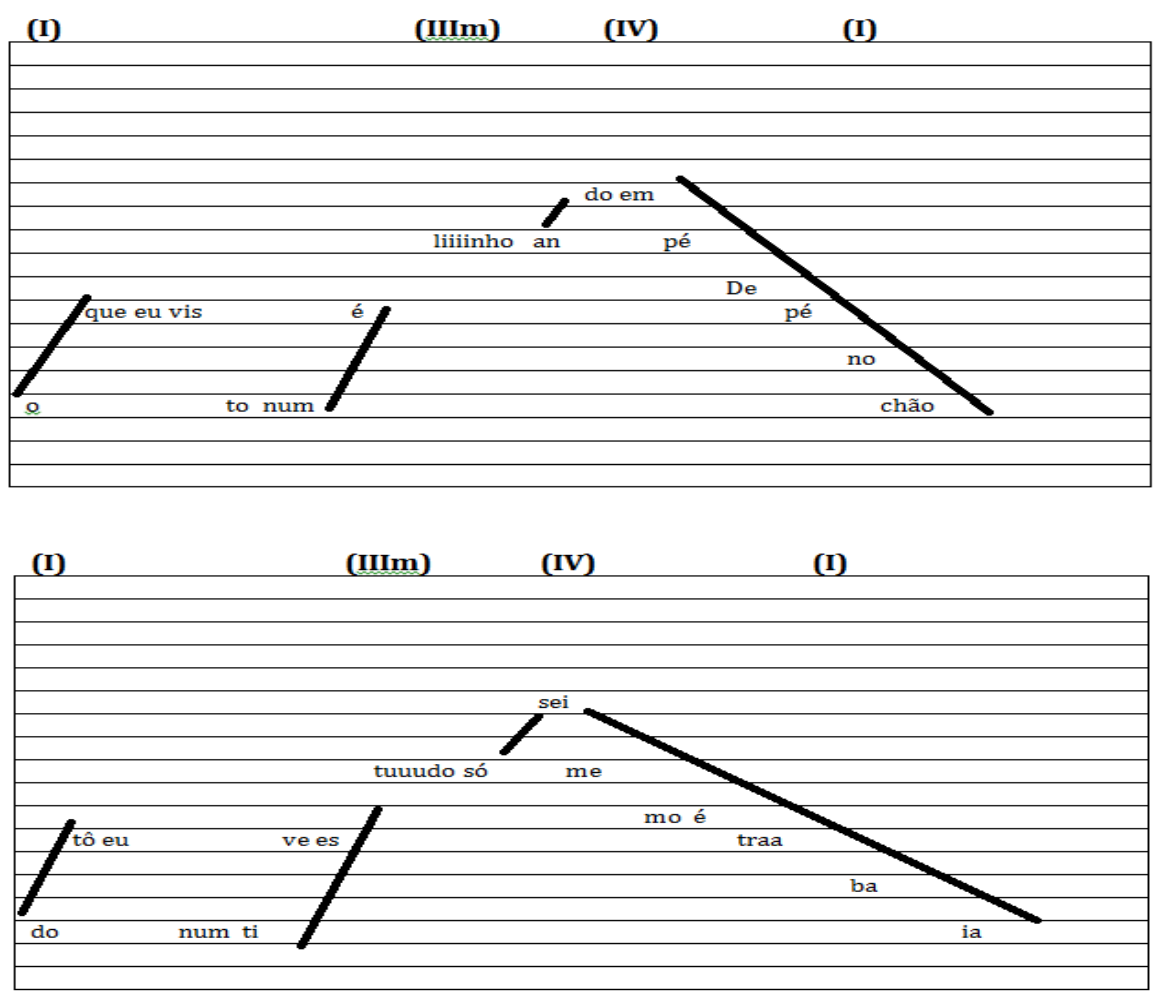

Notemos que, do ponto de vista estrutural, há preservação do perfil melódico e da cadência harmônica. Não obstante, as seleções da rede

TradTerm, São Paulo, v.38, fevereiro/2021, p. 116-141

Número Especial - III JOTA www.revistas.usp.br/tradterm 
associativa notadas no eixo sintagmático da linguagem verbal produzem implicações no que diz respeito à panrítmica (MESCHONNIC 2006: 17), que podem ser vistas no diagrama à medida que se contêm os ataques consonantais que produzem 'aceleração' às canções (por ex. 'trabalhar' versus 'trabaiá) e se privilegia a duração das vogais. A ênfase às vogais propiciadas pelo dialeto caipira acarreta maior passionalização da canção, que parece ser mais lenta do que o é, e provê diminuição em termos de seus efeitos somáticos. A mudança do ritmo, que em alguma medida parece dialogar com a mudança do gesto vocal do cancionista (TATIT 2012: 20), intensifica a produção do efeito de verdade figurativa: ao se subjetivar de outro modo na linguagem, o cancionista altera seu gesto oral e se produz outros efeitos de sentido. Trata-se do trabalho da oralidade na produção de si.

Vejamos um trecho em cuja tradução parece favorecer o perfil melódico do ponto de vista estrutural. Trata-se dos versos 25 e 26 que compõem a reiteração melódica mensurada nos exemplos anteriores.

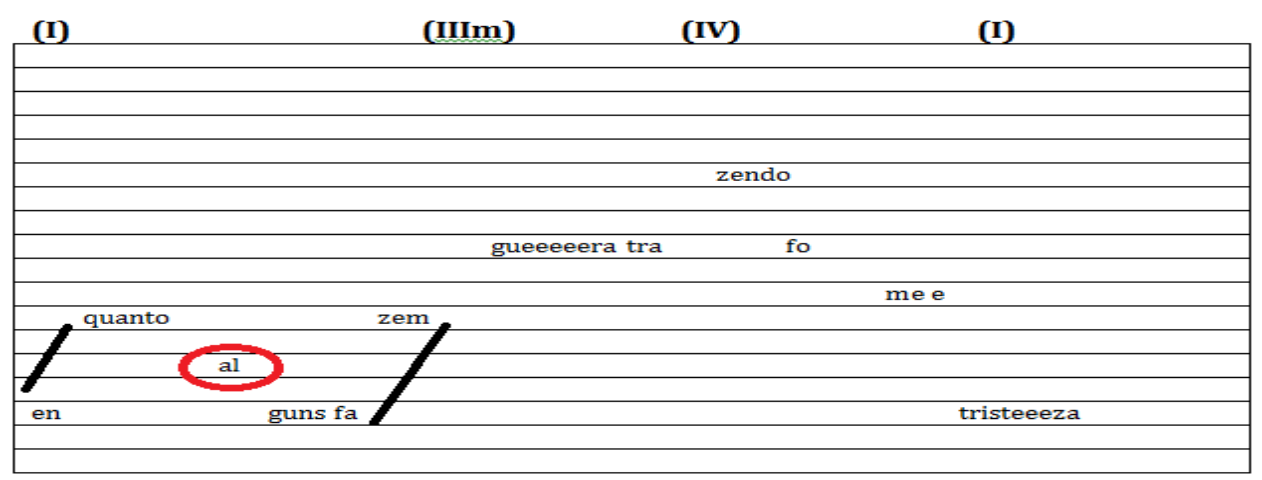

Nota-se, no diagrama acima (texto de 1992), a presença de certa ruptura com aquele perfil melódico mostrado nos exemplos anteriores: uma figura linguístico-melódica supostamente 'fora de lugar' (em vermelho) inicialmente destituída de propósito. Intencionalmente ou não, a regularidade estrutural parece ter sido recuperada na tradução de 2007: 


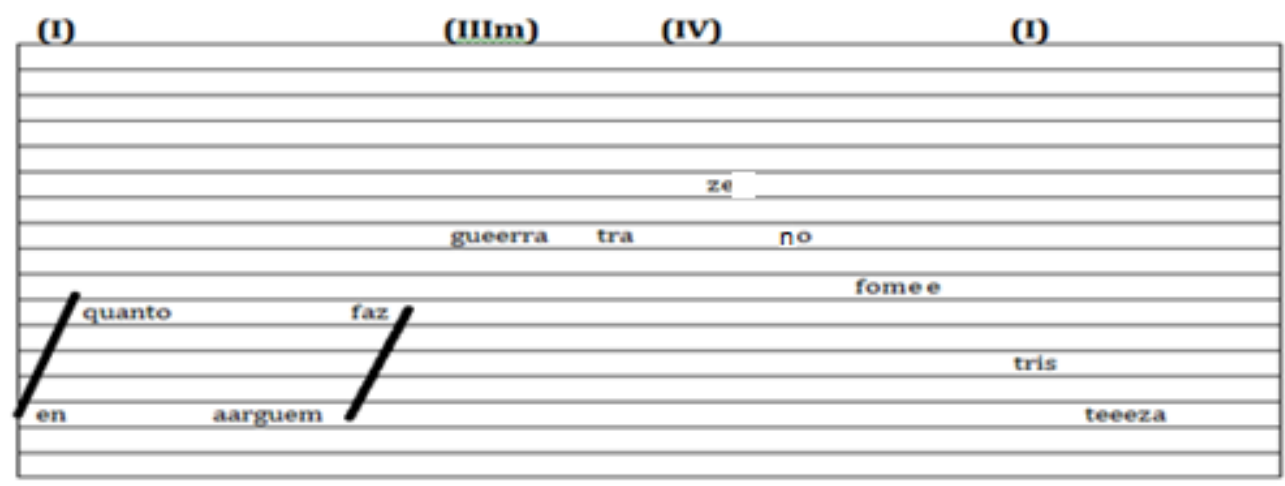

Encontramos, então, a manutenção do paralelismo do perfil melódico. A figura linguística (a partícula -al ou -ar constitutivo de 'alguém') é encaixada na continuidade da figura melódica. Se atentarmos ao verso subsequente, "trazendo fome e tristeza", verificamos novas dessemelhanças entre os textos de 1992 e 2007. A decisão pelo dileto caipira favorece a intensificação modal das paixões do sujeito e acarreta implicações favoráveis à manutenção de um perfil de alinhamento das unidades melódicas.

\section{Considerações}

Em sua complexa teoria do Ritmo, Meschonnic (2006; 2008) deixa claro não tratar do Ritmo da música, aquele que comporta o pulso ou andamento disposto em um tempo regular. Trato aqui da canção popular, aquela que corporifica a linguagem em sua tensão entre o ordinário e o performático (TATIT 2012: 190), que amplia senão abre possibilidades de subjetivações por meio das linguagens envolvidas.

É notório que Tatit (2012), ao propor a fala como germe da canção, extrai consequências relevantes, como as categorias 'dicção' como maneira de se cantar como se canta (a tensão entre o canto mais musicado e o menos musicado) e 'gesto oral do cancionista' (como o sujeito canta aquilo que canta), traços quase exclusivos por subordinações de ordem anatômicofisiológica. Já Meschonnic (2006: 5-9), ao tratar da oralidade em termos de indícios da subjetividade presente no falado e no escrito, parece atentar para como fazemos a linguagem fazer o que ela faz a partir das escolhas que fazemos no interior de um aparelho formal, bem como a capacidade de TradTerm, São Paulo, v.38, fevereiro/2021, p. 116-141

Número Especial - III JOTA www.revistas.usp.br/tradterm 
distintas subjetivações implicadas pela Panrítmica e pelo Ritmo (o diferente no mesmo, o mesmo no diferente).

Com essa abertura de debate, propõe-se compreender o objeto texto de canção a partir da interdependência de seus elementos estruturais, já sinalizada por Saussure (2006), Benveniste (1995) e desenvolvida por Meschonnic (2006; 2008); atentando para as implicações mútuas entre formaconteúdo em todos os níveis de análise na produção de significação. Por tratar-se de um texto sincrético que emerge em contextos particulares e também um produto cultural, torna-se necessário, ainda, entender aspectos discursivos para melhor compreensão de sua produção, distribuição, consumo e ainda a maneira como o texto - na condição de prática discursiva - contribui para o estabelecimento, manutenção ou subversão das relações de poder em dada contingência social, cultural, discursiva e histórica. 


\section{Referências}

Alonso, G. Caubóis do asfalto: música sertaneja e modernização brasileira. Tese de Doutorado apresentada ao Programa de Pós-graduação em História da Universidade Federal Fluminense. Niterói: UFF, 2011.

Benveniste, E. Os níveis de análise linguística. In: Problemas de linguística Geral, vol. 1, 4ª ed. Trad. Maria Glória Novak e Luiza Nieri. Campinas: Pontes, 1995.

CAIXETA, S. "Agora eu fiquei doce": o discurso da autoestima no sertanejo universitário. Dissertação de mestrado apresentada ao Programa de Pós-Graduação em Linguística e Língua Portuguesa da Universidade Estadual de Araraquara. Araraquara: FCLAr/UNESP, 2016.

CALDAS, W. Acorde na Aurora: música sertaneja e indústria cultural. São Paulo: Ed. Nacional, 1977.

Chartier, R. A história cultural: entre práticas e representações. Trad. Maria Manuela Galhardo. Lisboa: Difel 1990.

ChARTIER, R. O que é um autor. Trad. Luzmara Curcino. São Carlos: EDUFSCar, 2012.

Chitãozinho; Xororó; Rezende; Debétio. Mano. In: Tempo (álbum). RCA Records Label, 1999.

CRESWELL, J. W. Projeto de pesquisa: método qualitativo, quantitativo e misto. Porto Alegre: Artmed, 2010.

DIETRICH, P. Plano da expressão musical: níveis de descrição. In: Estudos Semióticos, São Paulo, n. 2, 2006. Disponível em: <https://doi.org/10.11606/issn.1980-4016.esse.2006.49162>. Acesso em: 14 jan. 2021.

Fairclough, N. Discurso e Mudança Social. Trad. Izabel Magalhães (coord.). Brasília, DF: Editora Universidade de Brasília, 2001.

Foucault, M. A arqueologia do saber. $8^{\mathrm{a}}$ ed. Trad. Luiz Felipe Beata Neves. Rio de Janeiro: Forense Universitária, 2012.

HAN, B-C. Bom entretenimento: uma desconstrução da história da paixão ocidental. Trad. Lucas Machado. Petrópolis/RJ: Vozes, 2019.

JAKOBSON, R. Aspectos linguísticos da tradução. In: Linguística e comunicação. Trad. Izidoro Blikstein e José Paulo Paes São Paulo. São Paulo: Cultrix, 2008.

LACERDA, O. Teoria elementar da música. São Paulo: Record Brasileira, 1961.

TradTerm, São Paulo, v.38, fevereiro/2021, p. 116-141

Número Especial - III JOTA

www.revistas.usp.br/tradterm 
LIMA, T. "Processo de releitura da canção Caipira (Joel Marques, 1992)". Comunicação pessoal. [Whatsapp, 11 nov. 2019].

Low, P. The Pentathlon Approach to Translating Songs. In: GoRLÉE, D. L. (org.). Song and Significance - Virtues and Vices of Vocal Translation. New York: Rodopi, 2005.

MARCIANO; RosSI, D. Fio de Cabelo. In: Somos apaixonados (álbum). Intérprete: Chitãozinho \& Xororó. Rio de Janeiro: Copacabana, 1982.

MARQues, J.; MACARAí. Caipira. In: Planeta azul (álbum). Intérprete: Chitãozinho \& Xororó. São Paulo: Polygram, 1992.

MARQues, J.; MACARAí. Caipira. In: Grandes clássicos da música sertaneja Vol. 1 (álbum). Intérprete: Chitãozinho \& Xororó. São Paulo: Radar Records, 2007.

MESCHONNIC, H. Linguagem Ritmo e vida. Trad. Cristiano Florentino. Belo Horizonte: FALE, 2006.

Meschonnic, H. Poética de traduzir. Trad. Jerusa Pires Ferreira e Suely Fenerich. São Paulo, Perspectiva, 2010.

Neiva, A. N. Chitãozinho \& Xororó: Nascemos para cantar. São Paulo: Prêmio, 2002.

OliveIRA, A. S. O modelo semiótico de Luiz Tatit e suas implicações na análise da canção popular no Brasil: algumas considerações iniciais. Linguagem - Estudos e Pesquisas, v. 16, n. 02, p. 131-147, jul/dez 2012.

Piovezani, C. A voz do povo: breve genealogia de uma longa história de discriminações. São Paulo: Vozes, 2020.

PYM, A. Explorando teorias da tradução. Trad. Rodrigo Borges de Faveri, Claudia Borges de Favere e Juliana Steil. São Paulo: Perspectiva, 2017.

RIBEIRO, D. O Povo Brasileiro: A formação e o sentido de Brasil. 2a ed. São Paulo: Companhia das Letras, 1995.

Santos, J. C. R. "Ai se eu te pego!" - um caso de (in)fidelidade: uma leitura holística do hit e suas traduções à luz da Análise Crítica do Discurso e dos Estudos de Tradução. Dissertação de mestrado apresentada ao Programa de Pós-Graduação em Linguística da Universidade Federal de São Carlos. São Carlos: UFSCar, 2019.

Saussure, F. Curso de Linguística Geral. Trad. Antônio Chelini, José Paulo Paes e Izidoro Blikstein. São Paulo: Cultrix, 2006. 
TATIT, L. O cancionista: composição de canções no Brasil. São Paulo: Editora da Universidade de São Paulo, 2012.

TATIT, L. Semiótica da canção: música e letra. São Paulo: Escuta, 1995.

TATIT, L. Elementos de análise da canção popular. Cadernos de semiótica aplicada. v. 1, n. 2, dez. 2003.

Treece, D. Melodia, texto e 0 cancionista de Luiz Tatit. Revista Teresa Revista de Literatura Brasileira. FFCHL/Editora 34, n. 4 e 5, 2003. Disponível em:

http://www.revistas.usp.br/teresa/article/view/116391/113976. Acesso em: 14 jan. 2021.

Recebido em: 10/03/2020

Aceito em: 22/09/2020

Publicado em fevereiro de 2021

TradTerm, São Paulo, v.38, fevereiro/2021, p. 116-141

Número Especial - III JOTA

www.revistas.usp.br/tradterm 